\title{
Factors associated with low Apgar in newborns in birth center
}

\author{
Fatores associados ao baixo Apgar em recém-nascidos em centro de parto \\ Factores asociados al bajo Apgar en recién nacidos en centro de parto
}

Nágela Cristine Pinheiro Santos'

ORCID: 0000-0002-6492-8372

Sibylle Emilie Vogt ${ }^{1}$

ORCID: 0000-0001-9553-4096

Elysângela Dittz Duarte"

ORCID: 0000-0001-8170-7523

Adriano Marçal Pimenta" ORCID: 0000-0001-7049-7575

Lélia Maria Madeira'

ORCID: 0000-0002-2882-869X

Mery Natali Silva Abreu"

ORCID: 0000-0002-6691-3537

' Hospital Sofia Feldman. Belo Horizonte, Minas Gerais, Brazil. "Universidade Federal de Minas Gerais. Belo Horizonte, Minas Gerais, Brazil.

How to cite this article:

Santos NCP, Vogt SE, Duarte ED, Pimenta AM, Madeira LM, Abreu MNS. Factors associated with low Apgar in newborns in birth center. Rev Bras Enferm. 2019;72(Suppl 3):297-304 doi: http://dx.doi.org/10.1590/0034-7167-2018-0924

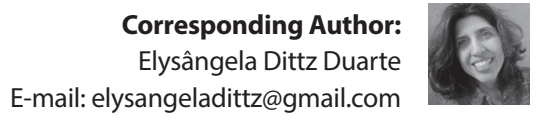

Submission: 07-21-2019 Approval: 05-07-2019

\section{ABSTRACT}

Objective: to analyze factors associated with Apgar of 5 minutes less than 7 of newborns of women selected for care at the Center for Normal Birth (ANC). Method: a descriptive crosssectional study with data from 9,135 newborns collected between July 2001 and December 2012. The analysis used absolute and relative frequency frequencies and bivariate analysis using Pearson's chi-square test or the exact Fisher. Results: fifty-three newborns (0.6\%) had Apgar less than 7 in the 5 th minute. The multivariate analysis found a positive association between low Apgar and gestational age less than 37 weeks, gestational pathologies and intercurrences in labor. The presence of the companion was a protective factor. Conclusion: the Normal Birth Center is a viable option for newborns of low risk women as long as the protocol for screening low-risk women is followed.

Descriptors: Apgar Score; Natural Childbirth; Obstetric Nursing; Humanizing Delivery; Labor, Obstetric.

\section{RESUMO}

Objetivo: analisar os fatores associados ao Apgar de quinto minuto menor do que sete de recém-nascidos de mulheres selecionadas para a assistência no Centro de Parto Normal (CPN). Método: estudo descritivo transversal com dados de 9.135 recém-nascidos, coletados entre julho de 2001 e dezembro de 2012. Na análise foi utilizada a apuração de frequências absolutas e relativas das variáveis e análise bivariada mediante o cálculo dos testes de quiquadrado de Pearson ou exato de Fisher. Resultados: 53 recém-nascidos $(0,6 \%)$ tiveram Apgar menor que sete no quinto minuto. A análise multivariada encontrou associação positiva entre baixo Apgar e idade gestacional menor que 37 semanas, patologias na gestação e intercorrências no trabalho de parto. A presença do acompanhante foi um fator protetor. Conclusão: o CPN é uma opção viável para recém-nascidos de mulheres de baixo risco desde que o protocolo de seleção das mulheres de baixo risco seja seguido.

Descritores: Índice de Apgar; Parto Normal; Enfermagem Obstétrica; Parto Humanizado; Trabalho de Parto.

\section{RESUMEN}

Objetivo: analizar los factores asociados al Apgar de quinto minuto menor que siete de los recién nacidos de mujeres, seleccionadas para la asistencia en el Centro de Parto Normal (CPN). Método: estudio descriptivo transversal con datos de 9.135 recién nacidos, recogidos entre julio de 2001 y diciembre de 2012. En el análisis se utilizaron el escrutado de frecuencias absolutas y relativas de las variables y el análisis bivariado mediante el cálculo de la prueba de Chi-cuadrado de Pearson o prueba exacta de Pearson Fisher. Resultados: cincuenta y tres recién nacidos $(0,6 \%)$ tuvieron Apgar menor que siete en el quinto minuto. El análisis multivariado encontró asociación positiva entre bajo Apgar y edad gestacional menor que 37 semanas, patologías en la gestación e interocurrencias en el trabajo de parto. La presencia del acompañante fue un factor protector. Conclusión: el CNP es una opción viable para los recién nacidos de mujeres de bajo riesgo desde que siga el protocolo de selección de las mujeres de bajo riesgo.

Descriptores: Puntaje de Apgar; Parto Normal; Enfermería Obstétrica; Parto Humanizado; Trabajo de Parto. 


\section{INTRODUCTION}

Just as the labor constitutes, in most cases, a physiological event for women, the birth must also be understood from the same perspective. Approximately $85 \%$ of newborns have a transition to extrauterine life without any difficulty and require little or no care at this time ${ }^{(1)}$. About $10 \%$ start breathing with stimulation and about $5 \%$ require some more complex care to start breathing after birth. Of the latter, $3 \%$ require positive pressure ventilation and $2 \%$ need to be intubated to ensure adequate ventilatory support ${ }^{(2)}$.

Although all the technology necessary for resuscitation should be available in the delivery room, assistance to the healthy newborn at the time of birth should facilitate the contact between mother and child and breastfeeding shortly after delivery. Interventions should only be performed when necessary ${ }^{(3)}$. However, in Brazil, care to newborns considered healthy at the time of their birth is characterized by the excess of interventions that are mostly unnecessary, which can interfere with mother-child bonding without bringing benefits to any of them. Research, including 18,639 newborns of single pregnancies weighing $\geq 2,500 \mathrm{~g}$ and Apgar at the first minute $\geq 7$, shows use of inhaled oxygen in $8.8 \%$ of the cases, upper airway and gastric aspiration in $71 \%$ and $39.5 \%$, respectively, and use of incubator in $8.7 \%$ of the newborns. Only $28.2 \%$ were placed in skin-to-skin contact with the mother, for $16.1 \%$ the maternal breast was offered in the delivery room, $69 \%$ were in rooming-in, and $45.5 \%$ were breastfed in the first hour of life ${ }^{(4)}$. The discrepancy between the professional practice and the scientific evidence in the care provided to healthy newborns reaffirms the urgent need for change in the current care model.

It is necessary to adopt a balanced model, which ensures the safety of women and their newborns with interventions according to the need and that favor the physiological evolution when intercurrences are not observed ${ }^{(5)}$. Different strategies have been adopted to achieve a model of humanized care for labor and birth with the use of appropriate technology and elimination of unnecessary interventions in the care for healthy newborns. Normal Delivery Centers (NDC) are situated in this context with care geared toward the physiology of parturition and the individuality of women, their newborns and their families(6).

In Brazil, the place of extra-hospital birth is still controversial. Questions are raised regarding the safety of care in NDCs for newborns, since their team consists of obstetric nurses and nursing technicians, according to the Brazilian Ministry of Health ${ }^{(7)}$. The absence of pediatrician restricts the complete care for newborns who need all stages of resuscitation, a possibility also present, although less likely, in low-risk births.

The national literature on perinatal outcomes of care in NDC is scarce. Vogt et al. ${ }^{(8)}$ found prevalence of low Apgar score of $0.4 \%$ for newborns of women at habitual risk in two hospitals in Belo Horizonte and no case in the NDC. Other studies in NDC show prevalence of $0.1 \%(9-10)$.

Even in low prevalence, the birth of a newborn with low Apgar score at the fifth minute and with demand for resuscitation represents an adverse event that requires immediate and precise interventions of the obstetric nurse in the NDC. A more detailed analysis of this adverse neonatal condition occurring among low-risk women may contribute to improve the safety of birth in this care space. It should be noted that, although the NDC is a care model proposed by Brazilian public policy for women with low-risk pregnancies, it is still much discussed in academia and among service managers.

\section{OBJECTIVE}

Analyze the factors associated with low Apgar score at the fifth minute (Apgar $<7$ ) of newborns from women selected for care in the NDC.

\section{METHOD}

\section{Ethical aspects}

The study was conducted according to the recommendations of Resolution no. 466/2012 of the National Health Council. Approved by the Research Ethics Committee of the Sofia Feldman Hospital (CAAE 11904812.2.0000.5132) which dismissed the application of the Free and Informed Consent Form, considering that the data source were the medical records and anonymity was ensured.

\section{Type of study}

This is an analytical and transversal retrospective study.

\section{Study setting}

The research was conducted in a peri-hospital NDC of a philanthropic maternity hospital located in the outskirts of Belo Horizonte. The institution has $100 \%$ of its resources coming from the Unified Health System (SUS). In the NDC, women are provided care in a proportion of one professional for one or two parturients. Care is performed by obstetric nurses who also perform shifts at the reference hospital to maintain bonding, quality, continuity of care and communication between the hospital and NDC teams. Women admission to the NDC follows a specific protocol with the following criteria: spontaneous labor in active phase, between 37 and 41 weeks of gestation, with single gestation, cephalic presentation, absence of meconium, without obstetric and/or clinical complications during pregnancy and presence of normal cardio-fetal heartbeat at admission, with rupture of membranes of up to 6 hours, without previous caesarean section or gynecological surgery, and whose fetuses present an estimated weight between $2500 \mathrm{~g}$ and $4000 \mathrm{~g}$. These criteria characterize the women as of low risk.

\section{Population and sample}

The study analysis was by intention-to-treat principle, therefore, all women admitted to the NDC participated in the study regardless of whether the birth place was the NDC itself or the reference maternity, when transfer was required.

All deliveries performed in the period from June 2001 to December 2012 were considered to define the sample, totaling 11,194 deliveries. Due to data availability we collected information from a total of 9,585 deliveries, which ensured a proportional distribution within each year analyzed, a significance level of $1 \%$ and accuracy of $1.5 \%$. 


\section{Data collection and organization}

Data were collected through review of medical records, using an instrument prepared, tested and validated by the researchers. This instrument included maternal information on age, skin color, education, parity, previous pathologies (urinary tract infection, toxoplasmosis, previous arterial hypertension, preeclampsia, eclampsia, type 1 or 2 diabetes, gestational diabetes, cardiopathy/nephropathy, violence, infertility, genitourinary surgery, among others). Intercurrence during pregnancy (urinary tract infection, toxoplasmosis, gestational diabetes with diet control, threat of preterm delivery, hemorrhage, anemia), smoking and drug use, number of prenatal consultations, obstetric conditions (gestational age, active phase of labor at admission, meconium liquid, prolonged labor), intercurrence during labor (shoulder dystocia, cord prolapse, intrapartum bleeding, nonreassuring fetal status), care characteristics (use of oxytocin, amniotomy, partogram, companion, analgesia, maternal position in the second stage of labor).

Data collection was carried out between April and October 2013 by previously trained undergraduate researchers. The data were registered directly into a digital form that fed the database. The collected data were reviewed by the researchers and any inconsistencies were checked and corrected by reviewing the corresponding medical record.

\section{Data analysis}

From the sample of 9,585 newborns, 450 newborns were excluded from the analysis due to lacking data. The final sample consisted of 9,135 newborns. We presented the absolute and relative frequencies of the variables and bivariate analysis for the variables of exposure and outcome, the Apgar score $<7$ at the fifth minute of life by calculating the Pearson's chi-square or Fisher's exact tests. The exposure variables already consolidated in the literature as risk factors for the outcome, as well as those that presented statistical significance below 0.20 $(p<0.20)$ during the bivariate analysis, were considered in the preparation of the final model.

We adjusted potentially inaccurate variables by using the binary logistic regression technique through the step-by-step strategy, with inclusion of all variables selected during the bivariate analysis in descending order of statistical significance. Variables that presented $p>0.05$ were removed one by one from the model and considered definitively excluded, if the decrease in the explanation of the outcome was not statistically significant.

The statistical significance level established for the multivariate analysis was $5 \%(p<0.05)$. The data were analyzed using Stata statistical software (version 13.1).

\section{RESULTS}

Of the total 9,135 newborns included in the study, 53 newborns ( $0.6 \%$ ) showed Apgar score below seven at the fifth minute.
Regarding sociodemographic characteristics (Table 1), most mothers analyzed had brown/black skin color and were aged 20-35 years. Educational level showed homogeneous distribution with one third of the sample distributed to elementary education, one third to secondary education, and one third to higher education.

As for the characteristics of the pregnancy (Table 2), a little more than half was multiparous and almost all were at gestational age between 37 and 41 weeks. The prevalence of pathology during pregnancy was higher compared with the clinical antecedents and almost twice as many women presented some morbidity during gestation. One third of the women did not have the adequate number of prenatal consultations as established by the Brazilian Ministry of Health.

Table 1 - Sociodemographic characteristics of the population associated with Apgar $<7$ at the fifth minute, Centro de Parto Normal, Belo Horizonte, Minas Gerais, Brazil, 2001-2012

\begin{tabular}{|c|c|c|c|c|c|c|c|}
\hline \multirow{2}{*}{ Variables } & \multicolumn{2}{|c|}{ Population } & \multicolumn{5}{|c|}{ Apgar $<7$ at the 5 th minute } \\
\hline & $\mathbf{n}$ & $\%$ & $\mathbf{n}$ & $\%$ & OR & $95 \% \mathrm{Cl}$ & $p$ value \\
\hline \multicolumn{8}{|l|}{ Skin color } \\
\hline White & 1.984 & 21.7 & 8 & 0.4 & 1.00 (ref.) & - & - \\
\hline Brown/Black & 4.792 & 52.5 & 33 & 0.7 & 1.71 & $0.79-3.71$ & 0.173 \\
\hline Yellow/indigenous & 86 & 0.9 & 0 & 0.0 & * & * & $*$ \\
\hline No data & 2.273 & 24.9 & 12 & 0.5 & 1.31 & $0.53-3.21$ & 0.554 \\
\hline \multicolumn{8}{|l|}{ Educational level } \\
\hline Up to 7 years & 2.676 & 29.3 & 11 & 0.4 & 1.00 (ref.) & - & - \\
\hline 8 to 10 years & 2.859 & 31.3 & 20 & 0.7 & 1.71 & $0.82-3.57$ & 0.155 \\
\hline 11 years or more & 2.806 & 30.7 & 19 & 0.7 & 1.65 & $0.78-3.48$ & 0.186 \\
\hline No data & 794 & 8.7 & 3 & 0.4 & 0.92 & $0.26-3.30$ & 0.897 \\
\hline \multicolumn{8}{|l|}{ Mother's age (years) } \\
\hline 20 to 35 & 6.612 & 72.4 & 36 & 0.5 & 1.00 (ref.) & - & - \\
\hline 10 to 14 & 62 & 0.7 & 1 & 1.6 & 2.99 & $0.40-22.19$ & 0.283 \\
\hline 15 to 19 & 2.123 & 23.2 & 14 & 0.7 & 1.22 & $0.65-2.25$ & 0.542 \\
\hline$\geq 36$ & 338 & 3.7 & 2 & 0.6 & 1.09 & $0.26-4.53$ & 0.909 \\
\hline
\end{tabular}

Table 2 - Characteristics related to the pregnancy and antecedents of the population associated with Apgar score $<7$ at the fifth minute, Centro de Parto normal, Belo Horizonte, Minas Gerais, Brazil, 2001-2012

\begin{tabular}{|c|c|c|c|c|c|c|c|}
\hline \multirow{2}{*}{ Variables } & \multicolumn{2}{|c|}{ Population } & \multicolumn{5}{|c|}{ Apgar $<7$ at the 5 th minute } \\
\hline & $\mathbf{n}$ & $\%$ & $\mathbf{n}$ & $\%$ & OR & $95 \% \mathrm{Cl}$ & $p$ value \\
\hline \multicolumn{8}{|l|}{ Parity } \\
\hline Primiparous & 3.988 & 43.7 & 29 & 0.7 & 1.00 (ref.) & - & - \\
\hline Multiparous & 5.138 & 56.3 & 24 & 0.5 & 0.64 & $0.37-1.10$ & 0.108 \\
\hline \multicolumn{8}{|l|}{$\begin{array}{l}\text { Gestational age } \\
\text { (weeks) }\end{array}$} \\
\hline 37 to 40 & 8.625 & 94.4 & 50 & 0.6 & 1.00 (ref.) & - & - \\
\hline$<37$ & 64 & 0.7 & 2 & 3.1 & 5.53 & $1.32-23.24$ & 0.019 \\
\hline$\geq 41$ & 446 & 4.9 & 1 & 0.2 & 0.39 & $0.05-2.80$ & 0.346 \\
\hline \multicolumn{8}{|l|}{ Smoker } \\
\hline No & 7.774 & 84.8 & 43 & 0.6 & 1.00 (ref.) & - & - \\
\hline Yes & 948 & 10.4 & 5 & 0.5 & 0.95 & $0.38-2.40$ & 0.913 \\
\hline No data & 443 & 4.8 & 5 & 1.1 & 2.04 & $0.81-5.19$ & 0.132 \\
\hline \multicolumn{8}{|c|}{ Antecedent pathology } \\
\hline None & 8.360 & 91.5 & 45 & 0.5 & 1.00 (ref.) & - & - \\
\hline Some & 775 & 8.5 & 8 & 1.0 & 1.93 & $0.91-4.10$ & 0.089 \\
\hline \multicolumn{8}{|c|}{ Current pathology } \\
\hline None & 7.740 & 84.7 & 39 & 0.5 & 1.00 (ref.) & - & - \\
\hline Some & 1.395 & 15.3 & 14 & 1.0 & 2.00 & $1.08-3.70$ & 0.027 \\
\hline \multicolumn{8}{|c|}{ Prenatal consultations } \\
\hline$\geq 6$ & 6.376 & 69.8 & 41 & 0.6 & 1.00 (ref.) & - & - \\
\hline$<6$ & 2.759 & 30.2 & 12 & 0.4 & 0.67 & $0.35-1.29$ & 0.232 \\
\hline
\end{tabular}


Table 3 - Birth-related characteristics of the population associated with Apgar score $<7$ at the fifth minute, Centro Parto Normal, Belo Horizonte, Minas Gerais, Brazil, 2001-2012

\begin{tabular}{|c|c|c|c|c|c|c|c|}
\hline \multirow{2}{*}{ Variables } & \multicolumn{2}{|c|}{ Population } & \multicolumn{5}{|c|}{ Apgar $<7$ at the 5 th minute } \\
\hline & n & $\%$ & $\mathbf{n}$ & $\%$ & OR & $95 \% \mathrm{Cl}$ & $p$ value \\
\hline \multicolumn{8}{|c|}{ Meconium liquid } \\
\hline No & 7.500 & 82.1 & 41 & 0.6 & 1.00 (ref.) & - & - \\
\hline Yes & 893 & 9.8 & 8 & 0.9 & 1.64 & $0.77-3.52$ & 0.200 \\
\hline No data & 742 & 8.1 & 4 & 0.5 & 0.99 & $0.35-2.76$ & 0.979 \\
\hline \multicolumn{8}{|l|}{ Oxytocin } \\
\hline No & 6.326 & 69.3 & 36 & 0.6 & 1.00 (ref.) & - & - \\
\hline Yes & 2.809 & 30.7 & 17 & 0.6 & 1.06 & $0.60-1.90$ & 0.834 \\
\hline \multicolumn{8}{|l|}{ Partogram } \\
\hline Yes & 7.042 & 77.1 & 44 & 0.6 & 1.00 (ref.) & - & - \\
\hline No & 2.093 & 22.9 & 9 & 0.4 & 0.69 & $0.33-1.41$ & 0.306 \\
\hline \multicolumn{8}{|l|}{ Companion } \\
\hline Yes & 7.204 & 78.9 & 32 & 0.4 & 1.00 (ref.) & - & - \\
\hline No & 1.931 & 21.1 & 21 & 1.1 & 2.46 & $1.42-4.28$ & 0.001 \\
\hline \multicolumn{8}{|c|}{ Intercurrence in labor } \\
\hline No & 8.734 & 95.6 & 41 & 0.5 & 1.00 (ref.) & - & - \\
\hline Yes & 401 & 4.4 & 12 & 3 & 6.54 & $3.41-12.54$ & $<0.001$ \\
\hline \multicolumn{8}{|l|}{ Analgesia } \\
\hline No & 8.563 & 93.7 & 47 & 0.6 & 1.00 (ref.) & - & - \\
\hline Yes & 572 & 6.3 & 6 & 1.1 & 1.92 & $0.82-4.51$ & 0.134 \\
\hline \multicolumn{8}{|c|}{ Childbirth position } \\
\hline Vertical & 3.338 & 36.5 & 12 & 0.4 & 1.00 (ref.) & - & - \\
\hline Horizontal & 4.787 & 52.4 & 34 & 0.7 & 1.98 & $1.03-3.83$ & 0.042 \\
\hline Tub & 1.010 & 11.1 & 7 & 0.7 & 1.93 & $0.76-4.92$ & 0.167 \\
\hline \multicolumn{8}{|c|}{ Type of delivery } \\
\hline Vaginal & 8.917 & 97.6 & 47 & 0.5 & 1.00 (ref.) & - & - \\
\hline Forceps & 67 & 0.7 & 2 & 3 & 5.81 & $1.38-24.41$ & 0.016 \\
\hline Cesarean & 151 & 1.7 & 4 & 2.7 & 5.14 & $1.83-14.43$ & 0.002 \\
\hline \multicolumn{8}{|c|}{ Prolonged labor } \\
\hline No & 8.995 & 98.5 & 52 & 0.6 & 1.00 (ref.) & - & - \\
\hline Yes & 140 & 1.5 & 1 & 0.7 & 1.23 & $0.17-9.01$ & 0.834 \\
\hline
\end{tabular}

Table 4 - Final model of logistic regression of variables associated with Apgar $<7$ at the fifth minute, Centro de Parto Normal, Belo Horizonte, Minas Gerais, Brazil, 2001-2012

\begin{tabular}{lccc}
\hline Variables & OR & $\mathbf{9 5 \%} \mathbf{C l}$ & $\boldsymbol{p}$ value \\
\hline Gestational age (weeks) & & & \\
$\quad 37$ to 40 & 1.00 (ref.) & - & - \\
$\quad<37$ & 6.12 & $1.44-26.07$ & 0.014 \\
$\quad \geq 41$ & 0.36 & $0.05-2.66$ & 0.319 \\
Intercurrence in labor & & & \\
$\quad$ No & 1.00 (ref.) & & \\
$\quad$ Yes & 5.85 & $3.02-11.33$ & $<\mathbf{0 . 0 0 1}$ \\
Presence of companion & & & \\
$\quad$ Yes & 1.00 (ref.) & & \\
$\quad$ No & 2.24 & $1.28-3.92$ & 0.005 \\
Current pathology & & & \\
$\quad$ None & 1.00 (ref.) & & \\
$\quad$ Some & 1.87 & $1.01-3.48$ & 0.047 \\
\hline Note: $m o d e l$ fit $p$-value $=0.71$ & & & \\
\end{tabular}

to desire for analgesia and $4.2 \%$ due to intercurrences in labor.

Regarding the factors associated with Apgar score below seven at the fifth minute, in the bivariate analysis, no sociodemographic variable was related to the outcome (Table 1). On the other hand, higher prevalence of Apgar score below seven at the fifth minute $(p<0.05)$ was observed among newborns of mothers with some pathology during pregnancy (Table 2), with gestational age below 37 weeks, without presence of companion and intercurrence during labor and childbirth, as well as those who had delivery in the horizontal position, use of forceps or caesarean section (Table 3).

According to the results of the multivariate model (Table 4), a mother with gestational age below 37 weeks had a six-fold higher chance of having a baby with altered Apgar score than one with gestational age between 37 and 40 weeks. In addition, the occurrence of intercurrence in labor increased the chance of altered Apgar by five times. The absence of companion was associated with an increase of $124 \%$ in the chance of Apgar score below seven at the fifth minute. Finally, mothers with some pathology during pregnancy had an $87 \%$ higher chance of having a newborn with Apgar score below seven at the fifth minute.

\section{DISCUSSION}

The prevalence of Apgar $<7$ at the fifth minute is $0.6 \%$. Gestational age $<37$ weeks, intercurrences in labor, pathologies during pregnancy, and absence of companion had negative impact on Apgar score, increasing the chance of the newborn receiving Apgar score $<7$. No sociodemographic factor was associated with low Apgar

Regarding the factors directly related to labor and childbirth (Table 3), good practices, such as the use of partogram and the presence of companion, were used in most deliveries, while the horizontal position (lithotomy, recumbent and semirecumbent on bed) was adopted by half of the women. Acceleration with oxytocin by a third. Intercurrence during labor, prolonged labor, analgesia and meconium fluid occurred in less than $10 \%$ of deliveries. The rate of assisted delivery (forceps) and cesarean section totalled $2.4 \%$.

Of the total number of women admitted to the NDC, $10.5 \%$ were transferred to the reference maternity hospital: $6.3 \%$ due score at the fifth minute. Analysis of the associated factors suggests that women who did not fit the NDC protocol were served, which directly impacted the vitality of the newborn.

Since the occurrence of unexpected intercurrences during labor can never be completely disregarded, the correct selection of women constitutes an indispensable element to maintain the prevalence of unfavorable conditions that threaten the health of newborns at a minimum level.

A systematic review with 11,795 women showed no significant difference in neonatal outcomes, comparing care modes in which 
newborn care was performed by obstetric nurse or obstetrician and hospital units that had the presence of physician ${ }^{(11)}$.

Regarding the prevalence of Apgar score $<7$ at the fifth minute, the international literature shows lower prevalences, but with no significant differences for care in Normal Birth Center, when compared with the care for low-risk women in the hospital(12-15). However, the prevalences are higher than in the present study. In extra-hospital NDC in Australia and New Zealand, the prevalence was $1.2 \%$ and $2 \%$, respectively ${ }^{(12-13)}$. In Denmark, the prevalence of Apgar score $<7$ at the first minute is below $2.5 \%{ }^{(14)}$. A Dutch study that included in the evaluation the care in intra-, peri- and extra-hospital NDC found Apgar score $<9$ at the fifth minute of life in $1.5 \%{ }^{(15)}$. The prevalence of $3.2 \%$ reported by Ferrazzi et al. ${ }^{(16)}$ for an intra-hospital NDC in Italy is an exception among the results of all the studies found. The prevalence of low Apgar scores in this institution may raise doubts regarding the objectivity of the Apgar method, as well as be related to a more flexible and less rigorous admission protocol.

Randomized international studies found prevalences between $0.7 \%$ and $1 \%$ with no significant differences for care in intrahospital NDC, a mode that has a more immediate service for emergencies than an extra-hospital unit ${ }^{(17-19)}$. National studies ${ }^{(8-10)}$, with prevalences of low Apgar score between $0.1 \%$ and $0.5 \%$, are consistent with international studies involving low-risk women, pointing to the NDC as appropriate place for labor and birth.

Recognizing that characteristics of extra-hospital and hospital modes may influence neonatal outcomes, some studies compare the results according to the specificity of the extra-hospital and hospital mode ${ }^{(20-21)}$. Prevalences of Apgar score $<7$ in deliveries of low-risk women, for 2006-2010 in New Zealand, were higher than those found in our study: $1.5 \%$ for home delivery, $1.7 \%$ for extra-hospital NDC, $2.3 \%$ for care in secondary hospital, and $2.8 \%$ in tertiary hospital. There was a gradual increase in the prevalence of low Apgar proportional to the increase in the complexity of the care mode ${ }^{(21)}$. Davis et al. ${ }^{(20)}$ observed risk of Apgar score $<7$ at the fifth minute in secondary and tertiary hospital $43 \%$ and $59 \%$ higher, respectively, than in delivery in primary care. These results may be related to subjectivity in the attribution of the Apgar score or to the bias of the professionals, who routinely deal with high-risk situations, in overvaluing slower, albeit physiological adaptations of some newborns. Another hypothesis for this difference would be the inappropriate and harmful use of interventions to accelerate labor. This practice may be present more routinely in hospital services of greater complexity.

A comparative study with information from the US Center for Disease Control (CDC) on care by obstetric nurse and obstetrician in hospital, normal delivery center, and home birth observed prevalence of Apgar at the fifth minute of $0.16 \%$ and $0.09 \%$ for hospital care by obstetrician and obstetric nurse, respectively, and higher prevalences for extra-hospital care ${ }^{(22)}$. It should be noted that the difference in the prevalence of Apgar between hospital care by obstetrician and obstetric nurse is significant and may suggest differences in the conduct of labor between both professionals.

Women with clinical conditions that did not correspond to the admission criteria established by the protocol were served in the NDC studied, as evidenced by the prevalence of $0.7 \%$ of prematurity, $8.5 \%$ of antecedent pathologies, and $15.3 \%$ of morbidities in the pregnancy. This same situation was documented in an English survey, which observed the presence of women with some risk factor (diabetes, preeclampsia, asthma, epilepsy, positive streptococci, IUGR, postdatism, among others) among the women who planned their delivery in an extra-hospital mode by obstetric nurse or obstetrician. Among those who planned a home birth, $7 \%$ presented some risk factor, $4 \%$ among the women admitted to a peri-hospital NDC and 3\% among those who planned their delivery in an extra-hospital or community NDC ${ }^{(23)}$.

The existence of pathologies during pregnancy is a criterion for choosing the place of delivery ${ }^{(24)}$. The selection of women for the NDC must comply strictly with the established protocol that excludes any maternal morbidity before or during pregnancy, since maternal morbid conditions can cause damage to the health of the newborn. Both the conscious choice of the mother for extra-hospital care and failures of the professionals such as transgression of the protocol or lack of attention in the admission and inadequate transfer of information in the admission process may be the causes for this fact.

The association, found in our study, between pathologies during pregnancy and low Apgar scores reinforces the importance of the correct selection of women for care in the NDC. The NDC is a delivery place specific for low-risk pregnant women and, in order to obtain the expected results with this care model, it is necessary to comply with the admission criteria. Although the more familiar ambience and the reduction of interventions in this environment are favorable characteristics for a worry-free evolution of labor, neonatal emergencies that threaten life can occur and in these situations the newborn requires appropriate care. Obstetric nurses should be highly trained for work in NDC, which includes training in neonatal resuscitation and early recognition of labor abnormalities.

Prematurity was present in the NDC studied in $0.7 \%$ of the deliveries served and was one of the factors associated with Apgar $<7$, corroborating other studies ${ }^{(25-26)}$. It constitutes serious risk to the survival of the newborn, requires care by a specialized team and access to appropriate technology feasible only in hospital institutions. To be admitted to the NDC, the parturient should present reliable data for calculation of gestational age, which enables excluding the admission of women with premature gestation. The birth of 64 preterm infants in the Normal Delivery Center indicates errors in the calculation of gestational age, since the conscious admission of women in preterm labor to the NDC is unlikely.

Exceptions in admission may have occurred in extreme situations, as well as discrepancies between the methods for calculating gestational age. Factors contributing to calculation error include late start of prenatal care and, consequently, access to ultrasound after the first trimester hindering the accurate estimation of gestational age. Again, it is highlighted the adequate selection of women for the delivery place as an important condition to ensure positive neonatal outcomes in non-hospital or small hospital modes. In this context, it is essential to ensure the presence of trained professional and adequate infrastructure to initiate immediate care for newborns and, if necessary, neonatal resuscitation. 
Intercurrences during labor, which may influence perinatal outcomes, are unpredictable and may arise even when there is correct selection of parturients. They occur both in hospital care and in NDC care. Data from hospital-based studies found association between cardiotocography alterations indicating nonreassuring fetal status and low Apgar scores. These studies did not find significant association between intercurrences that constitute emergencies such as cord prolapse, true knot, meconium, shoulder dystocia and placental abruption and low Apgar score at birth ${ }^{(27-28)}$. However, the intercurrences mentioned above constitute intrapartum emergencies that may require immediate intervention and availability of a specialized team, conditions which are limited or absent in the NDC.

The companion as a protection factor for low Apgar is supported by a systematic review ${ }^{(29)}$ with 22 clinical trials involving 15,288 women. In the study, the duration of labor of women who received continuous support was shorter, their probability of having cesarean delivery was lower $(\mathrm{RR}=0.78 ; 95 \% \mathrm{Cl}=0.67$ to 0.91$)$, as well as of having instrumental vaginal delivery (fixed effect, RR $=0.90 ; 95 \% \mathrm{Cl}=0.85$ to 0.96 ), of requiring regional analgesia ( $\mathrm{RR}$ $=0.93 ; 95 \% \mathrm{Cl}=0.88$ to 0.99 ), or of having a newborn with low Apgar score at the fifth minute $(\mathrm{RR}=0.69 ; 95 \% \mathrm{Cl}=0.50$ to 0.95$)$.

Inclusion of companion in delivery care, although ensured by law, is not yet routine in the country. In the research Nascer no Brasil, Diniz et al. ${ }^{(30)}$ recorded total absence of companion for $24.5 \%$ of the 23,879 women in the sample and presence at all times of care for $18.8 \%$. The continuous presence of a companion in our country is associated with the most favored social class and more frequent among white women with higher educational level, indicating the presence of inequalities in hospital care ${ }^{(30)}$. In the case of NDCs, which are included in the humanization of care, it is less likely that the presence or absence of companion is determined by institutional routines, but rather by the availability/unavailability of the companion at the time of delivery. The association between absence of companion and low Apgar score highlights the importance of the companion for positive outcomes of care.

This study is the first nationwide study involving 9,135 women served in a NDC. Its value lies in the high number of participants and in the possibility of evaluation over the 12 years of operation of the NDC. Since low Apgar score is an infrequent result, the sample of 9,135 women enabled a consistent analysis. Moreover, it shows a care model that is little prevalent and in opposition to the national context, since it consists in a care environment outside the hospital that proposes the obstetric nurse's autonomy as primary provider in labor and delivery.

\section{Limitations}

The data were collected retrospectively, based on the medical records of the puerperal women, newborns and do not involve other institutions.

An analysis of neonatal outcome including only women with labor and delivery in the NDC may present better results of neonatal Apgar scores when compared with an analysis by intention-to-treat principle, which includes women transferred in the intrapartum and which may present a potential for increased unfavorable neonatal outcomes.

\section{Contributions to the field of nursing, health or public policies}

It is considered that the quality of childbirth care is the object of discussion in different spheres of society, including the academic sphere and, also, a goal of public policies in Brazil, conferring high importance to the article. Care in a Normal Delivery Center is still innovative and the issue is quite controversial in academia and in the discussion among professional corporations. There are still few national studies examining the issue in depth. In this care space, obstetric nurses have a prominent role, being responsible for the entire labor, delivery, and birth process. The results presented may contribute to their work in NDCs, as well as show that this is a safe practice.

\section{CONCLUSION}

Newborns of low-risk women find in the NDC one more option for their birth with safety and quality. The low prevalence of newborns with Apgar $<7$ supports the national policy of implementation of NDCs, in pursuit of changing the care paradigm towards a care focused on the care for women and newborns. According to the results, obstetric nurses seemed to be professionals capable of providing safe care to this population in a differentiated environment of childbirth care. However, women selection according to protocol, excluding those with pathologies during pregnancy or prematurity, should be ensured in order to reduce the risk of damage to newborns. Access to more complex care should be ensured, as well as the competence of professionals working in the NDC. The baby's conditions at birth depend - in addition to maternal clinical history - on infrastructure for transfer and on constant training of human resources.

\section{FUNDING}

Fundação de Assistência Integral à Saúde.

\section{ERRATUM}

Article "Factors associated with low Apgar in newborns in birth center", with number of DOI: http://dx.doi. org/10.1590/0034-7167-2018-0924, published in the journal Revista Brasileira de Enfermagem, 72(Suppl 3):297-304, on page 297 :

Where to read:

How to cite this article:

Santos LFM, Janini JP, Souza VM, Santos RS. Transition to motherhood and mothering for women in wheelchairs: a nursing perspective. Rev Bras Enferm. 2019;72(Suppl 3):297-304. doi: http://dx.doi.org/10.1590/0034-7167-2018-0924

Read:

How to cite this article: Santos NCP, Vogt SE, Duarte ED, Pimenta AM, Madeira LM, Abreu MNS. Factors associated with low Apgar in newborns in birth center. Rev Bras Enferm. 2019;72(Suppl 3):297-304 doi: http://dx.doi.org/10.1590/0034-7167-2018-0924 


\section{REFERENCES}

1. Kattwinkel J, Perlman JM, Aziz K, Colby C, Fairchild K, Gallagher J, et al. Part 15: neonatal resuscitation: 2010 American Heart Association Guidelines for Cardiopulmonary Resuscitation and Emergency Cardiovascular Care. Circulation. 2010;122(18 Suppl 3):S909-19. doi: 10.1161/ CIRCULATIONAHA.110.971119

2. Perlman JM, Wyllie J, Kattwinkel J, Wyckoff MH, Aziz K, Guinsburg R, et al. Part 7: neonatal resuscitation: 2015 International Consensus on Cardiopulmonary Resuscitation and Emergency Cardiovascular Care Science With Treatment Recommendations. Pediatrics. 2015;136(Suppl 2):S120-66. doi: 10.1542/peds.2015-3373D

3. Organização Mundial de Saúde (OMS). United States Agency International Development (USAID). Maternal and Child Survival Program. Recomendações para o aumento do trabalho de parto [Internet]. Geneva: WHO; 2015 [cited 2018 Nov 10]. Available from: http://apps.who. int/iris/bitstream/handle/10665/174001/WHO_RHR_15.05_por.pdf;jsessionid=6414FB64406FC7EB8F7434B5FADF3112?sequence

4. Moreira MEL, Gama SGN, Pereira APE, Silva AAM, Lansky S, Pinheiro RS, et al. Clinical practices in the hospital care of healthy newborn infant in Brazil. Cad Saúde Pública. 2014;30(Suppl 1):S1-12. doi: 10.1590/0102-311X00145213

5. Marcolin AC. Qualidade e segurança: caminhos para o sucesso do redesenho do modelo de cuidado obstétrico. Rev Bras Ginecol Obstet. 2015;37(10):441-5. doi: 10.1590/SO100-720320150005472

6. Ministério da Saúde (BR). O modelo obstétrico e neonatal que defendemos e com o qual trabalhamos. Brasília: Ministério da Saúde; 2014.

7. Ministério da Saúde (BR). Portaria n 11, de 07 de janeiro de 2015. Redefine as diretrizes para implantação e habilitação de Centro de Parto Normal (CPN), no âmbito do Sistema Única de Saúde (SUS), para o atendimento à mulher e ao recém-nascido no momento do parto e do nascimento, em conformidade com o Componente PARTO E NASCIMENTO da Rede Cegonha, e dispõe sobre os respectivos incentivos financeiros de investimento, custeio e custeio mensal [Internet]. Brasília: Ministério da Saúde; 2015 [cited 2018 Oct 03]. Available from: http://bvsms.saude.gov.br/bvs/ saudelegis/gm/2015/prt0011_07_01_2015.html

8. Vogt SE, Silva KS, Dias MAB. Comparison of childbirth care models in public hospitals, Brazil. Rev Saúde Pública. 2014;48(2):1-10. doi: $10.1590 /$ S0034-8910.2014048004633

9. Lobo SF, Oliveira SMJV, Schneck CA, Silva FMB, Bonadio IC, Riesco MLG. Maternal and perinatal outcomes of an alongside hospital birth center in the city of São Paulo, Brazil. Rev Esc Enferm USP. 2010;44(3):812-8. doi: 10.1590/S0080-62342010000300037

10. Schneck CA, Gonzalez Riesco ML, Bonadio IC, Diniz CSG, Oliveira SMJV. Maternal and neonatal outcomes at an alongside birth center and at a hospital. Rev Saúde Pública. 2012;46(1):1-10. doi: 10.1590/S0034-89102012000100010

11. Hodnett ED, Downe S, Walsh D. Alternative versus conventional institutional settings for birth. Cochrane Database Syst Rev. 2012;(8):CD000012. doi: 10.1002/14651858.CD000012.pub4

12. Monk A, Tracy M, Foureur M, Grigg C, Tracy S. Evaluating Midwifery Units (EMU): a prospective cohort study of freestanding midwifery units in New South Wales, Australia. BMJ Open. 2014;4(10):e006252. doi:10.1136/bmjopen-2014-006252

13. Grigg CP, Tracy SK, Tracy M, Daellenbach R, Monk A, Schmied V, et al. Evaluating Maternity Units: a prospective cohort study of freestanding midwife-led primary maternity units in New Zealand-clinical outcomes. BMJ Open. 2017;7(8):e016288. doi:10.1136/bmjopen-2017-016288

14. Christensen LF, Overgaard C. Are freestanding midwifery units a safe alternative to obstetric units for low risk, primiparous childbirth? An analysis of effect differences by parity in a matched cohort study. BMC Pregnancy Childbirth. 2017;17:14. doi 10.1186/s12884-016-1208-1

15. Hermus MAA, Hitzert M, Boesveld IC, Dommelen PV, Franx A, Graaf JP, et al. Differences in optimality index between planned place of birth in a birth centre and alternative planned places of birth, a nationwide prospective cohort study in The Netherlands: results of the Dutch Birth Centre Study. BMJ Open. 2017;7(11):e016958. doi:10.1136/bmjopen-2017-016958

16. Ferrazzi E, Visconti E, Paganelli AM, Campi CM, Lazzeri C, Cirillo F, et al. The outcome of midwife-led labor in low-risk women within an obstetric referral unit. J Matern Fetal Neonatal Med. 2015;28(13):1530-6. doi:10.3109/14767058.2014.958995

17. Gottvall K, Waldenström U, Tingstig C, Grunewald C. In-hospital birth center with the same medical guidelines as standard care: a comparative study of obstetric interventions and outcomes. Birth. 2011;38(2):120-8. doi: 10.1111/j.1523-536X.2010.00461.X

18. Bernitz S, Rolland R, Blix E, Jacobsen M, Sjøborg K, Øian P. Is the operative delivery rate in low-risk women dependent on the level of birth care? A randomised controlled trial. BJOG. 2011;118(11):1357-64. doi: 10.1111/j.1471-0528.2011.03043.x

19. Begley C, Devane D, Clarke M, McCann C, Hughes P, Reilly M, et al. Comparison of midwife-led and consultant-led care of healthy women at low risk of childbirth complications in the Republic of Ireland: a randomised trial. BMC Pregnancy Childbirth. 2011;11:85. doi: 10.1186/1471-2393-11-85

20. Davis D, Baddock S, Pairman S, Hunter M, Benn C, Wilson D, et al. Planned place of birth in New Zealand: does it affect mode of birth and intervention rates among low-risk women? Birth. 2011;38(2):111-9. doi: 10.1111/j.1523-536X.2010.00458.x

21. Dixon L, Prileszky G, Guilliland K, Miller S, Anderson J. Place of birth and outcomes for a cohort of low risk women in New Zealand: A comparison with Birthplace England. N Z Coll Midwives J [Internet]. 2014 [cited 2018 Oct 02];50:11-8. Available from: https://www.midwife. org.nz/wp-content/uploads/2018/11/Jnl-50-art-2-Place-of-Birth.pdf

22. Grünebaum A, McCullough LB, Sapra KJ, Brent RL, Levene MI, Arabin B, et al. Apgar score of 0 at 5 minutes and neonatal seizures or serious 
neurologic dysfunction in relation to birth setting. Am J Obstet Gynecol. 2013;209(4):323.e1-6. doi: 10.1016/j.ajog.2013.06.025

23. Li Y, Townend J, Rowe R, Brocklehurst P, Knight M, Linsell L, et al. Perinatal and maternal outcomes in planned home and obstetric unit births in women at 'higher risk' of complications: secondary analysis of the Birthplace national prospective cohort study. BJOG. 2015;122(5):74153. doi: $10.1111 / 1471-0528.13283$

24. Ministério da Saúde (BR). Comissão Nacional de Incorporação de Tecnologias no SUS. Diretriz nacional de assistência ao parto normal [Internet]. Brasília: Ministério da Saúde; 2016 [cited 2018 Oct 03]. Available from: http://conitec.gov.br/images/Consultas/2016/ Relatorio_Diretriz-PartoNormal_CP.pdf

25. Cheng YW, Snowden JM, King TL, Caughey AB. Selected perinatal outcomes associated with planned home births in the United States. Am J Obstet Gynecol. 2013;209(4):325e1-8. doi: 10.1016/j.ajog.2013.06.022

26. Figueiró-Filho EA, Oliveira VM, Ferreira CM, Silva VM, Tinos ALS, Kanomata LB. Perinatal variables and association with very low birthweight newborns in a Brazilian public university hospital. Rev Bras Ginecol Obstet. 2014;36(1):10-6. doi: 10.1590/S0100-72032014000100004

27. De Zorzi PM, Madi JM, Rombaldi RL, Araújo BF, Zatti H, Madi SRC, et al. Perinatal factors associated with $\mathrm{pH}<7.1$ in umbilical artery and Apgar 5 min <7.0 in term newborn. Rev Bras Ginecol Obstet. 2012;34(8):381-5. doi: 10.1590/50100-72032012000800007

28. Salustiano EMA, Campos JADB, Ibidi SM, Ruano R, Zugaib M. Low Apgar scores at 5 minutes in a low risk population: maternal and obstetrical factors and postnatal outcome. Rev Assoc Med Bras. 2012;58(5):587-93. doi: 10.1590/S0104-42302012000500017

29. Hodnett ED, Gates S, Hofmeyr GJ, Sakala C, Weston J. Continuous support for women during childbirth. Cochrane Database Syst Rev. 2011;(2):CD003766. doi: 10.1002/14651858.CD003766

30. Diniz CSG, d'Orsi E, Domingues RMSM, Torres JA, Dias MAB, Schneck CA, et al. Implementation of the presence of companions during hospital admission for childbirth: data from the Birth in Brazil national survey. Cad Saúde Pública. 2014;30(Suppl 1):S140-53. doi: 10.1590/0102-311X00127013 